\title{
Epistemic Permissivism and Reasonable Pluralism
}

\author{
Richard Rowland and Robert Mark Simpson
}

\author{
In Michael Hannon and Jeroen de Ridder (Eds.), Routledge Handbook of \\ Political Epistemology (New York: Routledge, 2021)
}

Abstract. There is an intuitive difference in how we think about pluralism and attitudinal diversity in epistemological contexts versus political contexts. In an epistemological context, it seems problematically arbitrary to hold a particular belief on some issue, while also thinking it perfectly reasonable to hold a totally different belief on the same issue given the same evidence. By contrast, though, it doesn't seem problematically arbitrary to have a particular set of political commitments, while at the same time thinking it perfectly reasonable for someone in a similar position have a totally different set of political commitments. This chapter examines three explanatory theses that might be used to make sense of this difference: (l) that practical commitments are desire dependent in a way that beliefs are not; (2) that there are reasons to be resolute in practical commitments, but not in beliefs; and (3) that compromise in the face of practical political disagreement doesn't mitigate controversy, whereas compromise in the face of disagreement about mere beliefs does mitigate controversy.

\section{Pluralism and arbitrariness}

For a wide variety of questions we think every reasonable person should agree. The earth is not flat. Killing for fun is wrong. Pigs don't fly. But for many other things - perennial ethical debates, questions about aesthetic value, or about what it's reasonable to believe on (at least some) philosophical, religious, and scientific 
questions - we think informed people can rationally disagree. We will call this ethos, as loosely characterised, pluralism. ${ }^{1}$

Permissivism is a position in epistemology that seems to express a pluralistic ethos. It says there is sometimes more than one rational doxastic attitude that one may hold on some proposition, $\mathrm{P}$, given a particular body of evidence, $E .^{2}$ In political theory we find another expression of a pluralistic ethos in the position Rawls and his followers call Reasonable Pluralism. Reasonable Pluralism says that given the exercise of human reason under conditions of political freedom, people won't all converge upon a single worldview or life plan. They will, rather, adopt a diverse plurality of worldviews and related commitments. ${ }^{3}$

In this chapter we aim to make sense of some differences in how pluralism works in these two domains, the epistemic and political. In order to describe these differences, we need to distinguish two ways of expressing a pluralistic ethos in one's attitudes. One can either be abstemiously pluralistic or indulgently pluralistic. An abstemious pluralist thinks informed people can rationally adopt different stances on various questions, but he refrains from taking a stance on any such questions, and only takes stances where he thinks there is just one rationally acceptable attitude. An indulgent pluralist also thinks people can rationally adopt different stances on various questions, but she does take a stance on some of these contested questions. She thinks people can rationally disagree about God's existence, but she is a firm atheist. She thinks people can rationally disagree about the credibility of evolutionary psychology, but she sees it as hogwash. She thinks people can rationally disagree on whether reparations are owed to descendants of enslaved and colonised peoples, but she is in favour.

Indulgent pluralism in an epistemic context encounters a serious challenge, one that abstemious pluralism in an epistemic context seemingly doesn't. Suppose we

\footnotetext{
${ }^{1}$ One can have a pluralistic ethos without being a relativist. To think people can rationally disagree about e.g. ethical questions isn't necessarily to think ethical questions don't have objectively true answers. You may believe that there's a lot of uncertainty about what the answers are, such that people can rationally arrive at different conclusions.

${ }^{2}$ For recent defences of Permissivism see Schoenfield (2019) and Jackson (forthcoming). Many accounts of Permissivism distinguish interpersonal and intrapersonal versions of the view. The former says that there is sometimes more than one doxastic attitude that two agents can hold on proposition P given evidence $\mathrm{E}$; the latter says there is sometimes more than one doxastic attitude that the same agent can hold on $\mathrm{P}$ given $\mathrm{E}$.

${ }^{3}$ This characterisation of Reasonable Pluralism is paraphrased from Rawls (1993: xvi). In this context being reasonable means, roughly, seeking to abide by fair terms of social cooperation. A reasonable worldview isn't just one that's supported by reasons, then, it's a worldview that evinces a commitment to cooperating with others in the face of ongoing disagreement. There is a significant connection for Rawls, though, between reasonableness and the potential for rational disagreement. Roughly, reasonable people think political decisions shouldn't be based on judgements about which rational, informed people disagree (Ibid: 60, 138)
} 
have two incompatible propositions, $\mathrm{p}_{1}$ and $\mathrm{p}_{2}$. The worry is that there seems to be something rationally dubious about simultaneously thinking

(1) On the available information, it's reasonable to believe either $\mathrm{p}_{1}$ or $\mathrm{p}_{2}$, and

(2) For my part, I believe that $\mathrm{p}_{1}$.

Suppose you think there are apprehensible factors that speak in favour of believing $\mathrm{p}_{1}$ instead of $\mathrm{p}_{2}$. In that case it is difficult to make sense of (1), because by your own lights accepting $\mathrm{p}_{2}$ would mean failing to take account of apprehensible factors that impugn this option, and that seems irrational. Conversely, suppose you think there aren't any apprehensible factors that favour believing $\mathrm{p}_{1}$ instead of $\mathrm{p}_{2}$. In that case it seems like any reason you might have for (2), i.e. believing $\mathrm{p}_{1}$ instead of $\mathrm{p}_{2}$, must be an arbitrary pseudo-reason, like you simply 'taking a shine' to $\mathrm{p}_{1}$, and it seems irrational to believe on such bases. ${ }^{4}$ Several authors have discussed whether this arbitrariness worry ultimately makes Permissivism untenable. ${ }^{5}$ Permissivism sounds appealing in the abstract. But if you are a Permissivist on any question where you have your own views - if you're at all indulgent, rather than abstemious, in your Permissivism - then this dilemma instantly arises. Any reason for favouring your own view over others that you see as rationally permissible either undermines your meta-view about the rational permissibility of rival views, or else seems irrationally arbitrary. ${ }^{6}$

Intuitively, though, arbitrariness-based objections don't create the same worry for (indulgent) Reasonable Pluralism as for (indulgent) Permissivism. Upon honest reflection, most people recognise that they have arrived at their worldview and the practical life projects they are undertaking, in light of their worldview via accidents of circumstance, and hence that these commitments are arbitrary in an important sense. And while it can create a feeling of unease to acknowledge this arbitrariness, it generally doesn't seem to undermine people's sense of being committed to their projects. Unlike with beliefs, it can seem not only reasonable but indeed virtuous to be indulgently pluralistic in your worldview-based projects. Forswearing any projects or political commitments that are 'tainted' by arbitrariness seems somehow hyper-rationalistic, to the point of error. It's a little

\footnotetext{
${ }^{4}$ This is how the arbitrariness objection to Permissivism is presented in Simpson (2017), building on White's (2005) account. There are some problems that must be addressed by abstemious and indulgent Permissivists alike. For example (see Schultheis 2018), if you believe there's a range of permissible credences you might have in P, then you could hold a credence on the range's edge. But that credence will be rationally dominated by other credences nearer the middle of the range, because (a) you don't know the permissible range's exact boundaries, and (b) a credence nearer the edge seems at greater risk of falling outside the range. Therefore, one might argue, pace Permissivism, we aren't rationally permitted to hold any credence in a range of credences for a given proposition and body of evidence.

${ }^{5}$ Further to the above, see also Schoenfield (2014), and Stapleford (2019).

${ }^{6}$ What we're calling abstemious Permissivism is similar to what Sharadin (2017: 65) calls lower-case permissivism. Smith (2020) argues that Permissivists rationally ought to be abstemious, in something like our sense.
} 
bit like adopting an explicitly utilitarian mindset while trying to make friends, or choosing a football team to support based on its forecasted win ratio next season, rather than accidents of geography. Much like your friendships or sporting allegiances, your worldview-based projects seems like commitments that you can be virtuous in holding fast to, irrespective of the contingency in how you acquired them.

But does this double standard withstand scrutiny? Maybe we should see the influence of arbitrary factors in our worldview-based projects as a source of concern, much the same as we think of arbitrary factors in our beliefs. Here we examine three ways that one might seek to defend the discrepancy in how we think about arbitrary commitments across the two domains. Arbitrariness might be relatively unobjectionable in our worldview-based projects, because:

1. Practical rationality is desire-dependent, in a way that epistemic rationality isn't

2. We have reasons to be resolute in our practical commitments, but no analogous reasons to be resolute in our doxastic commitments, or

3. Compromise in the face of epistemic disagreement generally mitigates controversy, whereas compromise in the face of practical disagreement doesn't

We discuss these proposals in $\$ 2, \$ 3$, and $\$ 4$ respectively.

\section{Desire-dependence}

Many authors argue that what it is practically rational for you to do depends on your desires. Bernard Williams (1981), for instance, defends reasons internalism: some fact is a reason for you to $\varphi$ only if you could come to $\varphi$ by deliberating from your current motivations. A number of authors have held that our reasons for action are ultimately explained by our desires, or the desires of somewhat idealised versions of ourselves. ${ }^{7}$ If one of these views is right, then we can be indulgent practical pluralists. For we can hold that it is rational for us to $\varphi$ because $\varphi$-ing promotes our desires but that it is not rational for another to $\varphi$ because $\varphi$-ing does not promote their desires. It seems that we can explain the rationality of indulgent practical pluralism in this way even if we do not think that all our reasons are dependent on our desires: so long as we hold that sometimes one person has a reason to do one thing, which another does not have, we can hold that sometimes it is rational for us to do one thing whilst it is reasonable that others do another. And the actions that it is rational for us to perform do seem to vary with our desires in this way. Suppose that dancing will promote your desires but not your friend's because you want to dance and they don't. Intuitively, you have a

\footnotetext{
${ }^{7}$ For discussion see Finlay and Schroeder (2017).
} 
good reason to go to a dance party, which they do not have. The desire-dependence of practical reasons and rationality straightforwardly explains this. ${ }^{8}$

But epistemic rationality and reasons are not desire-dependent in the same way, so we might think. Whether or not it's rational for you believe $\mathrm{p}$ is primarily a matter of whether or not your evidence supports $\mathrm{p}$, and your desires don't have a bearing on what your evidence supports. If some piece of evidence is a reason to believe $\mathrm{p}$, then, so we ordinarily think, that evidence tells in favour of you believing $\mathrm{p}$ regardless of whether believing that $\mathrm{p}$ promotes one of your desires. We might think that even if A and B's desires are completely different, if their evidence is the same, their epistemic reasons and what it is rational for them to believe are the same. ${ }^{9}$

Some hold that epistemic reasons and rationality are entirely explained by our desires. But the most plausible versions of this view can still preserve an asymmetry between the desire-dependence of practical rationality and the desire-dependence of epistemic rationality. We might think that (a) everyone has the goal of believing the truth and avoiding error, because to be engaged in the activity of forming beliefs is just to have a goal along these lines, or that (b) whatever we desire, forming beliefs in line with our evidence promotes our desires better than not forming beliefs in line with our evidence, because having correct beliefs helps us get other things that we want. ${ }^{10}$ If either (a) or (b) hold, then - holding our evidence and background-beliefs fixed - epistemic reasons and rationality will not differ from person to person. But practical reasons and rationality depend on our particular contingent desires (e.g. a desire to dance) and what would promote these particular contingent desires. In this case, indulgent epistemic pluralism would not be epistemically rational because holding our evidence fixed what's rational for one of us to believe is what it is rational for another to believe, but the actions that it is rational for us to perform can vary from person to person based on our different particular desires: indulgent practical pluralism can be rational."

This difference in the desire-dependence of practical and epistemic rationality may explain why indulgent practical pluralism is rational in some cases. But some of those who hold that indulgent practical pluralism is rational (such as at least some Rawlsians) hold that it is rational in cases in which the practical rationality of our actions does not seem to depend on our desires. What we have most moral reason to do does not seem to depend on our particular desires. For instance, regardless of our (particular) desires, we have most moral reason to save a drowning child when we could easily do so. But practical indulgent pluralists think that

\footnotetext{
${ }^{8}$ See Schroeder (2007).

${ }^{9}$ See e.g. Shah (2006: 481) and Rowland (2012: 4-5).

${ }^{10}$ See e.g. Schroeder (2007: chapter 6) and Cowie (2014).

${ }^{11}$ Thanks to Josh DiPaolo for pressing us on this.
} 
there are many cases in which we can rationally hold fast to and pursue our moral views whilst insisting that other incompatible moral views are reasonable. For instance, according to some, it is rational to stand by and act in line with one's moral commitment that euthanasia is permissible whilst acknowledging that it is reasonable for others to hold that it is wrong and act accordingly. ${ }^{12}$ But the rationality of our moral commitments must be independent of our particular desires. So, the explanation of why such cases of practical indulgent pluralism is rational cannot be that the rationality of such practical commitments depends on our desires.

One option here would be to give up the view that moral reasons do not depend on our particular desires. Such a view may provide a good explanation of the contrast between indulgent practical pluralism and indulgent epistemic pluralism. However, we will set this aside as holding that moral reasons depend on our contingent desires is a controversial - and for many people, extremely counterintuitive - view. Another option would be to hold that although indulgent practical pluralism is sometimes rational, it is not in moral cases like that discussed above. But in the rest of this chapter we will investigate whether we can explain how a more capacious practical indulgent pluralism is rational even though indulgent epistemic pluralism is not.

\section{Resoluteness v. readiness to revise}

In general, you have a good reason to revise your beliefs upon receipt of evidence that tells against them. We speak of epistemic or doxastic commitments, but that term is slightly misleading, because in forming some token belief you aren't binding yourself to a mental state. You are forming a working, but ever-ready-to-berevised, picture of how things stand in the world. Rationality requires you to adjust this when you gain information that indicates an inaccuracy in it. And as a Permissivist you don't want to deny any of this. You may think there is more than one rational doxastic attitude to take towards $\mathrm{P}$ given $\mathrm{E}$, but you had still be (or had better be) working to get your picture right, vis-à-vis $\mathrm{P}$, and so you will still want to make your belief on $\mathrm{P}$ dynamically responsive to evidence. ${ }^{13}$

Practical commitments - including the projects people take on, in light of their worldviews - are different to this, in that they really are commitments. They are a matter of resolution in ways that beliefs are not, or at any rate shouldn't be. To

\footnotetext{
${ }^{12}$ See, for instance, Quong (2010: ch. 7).

${ }^{13}$ Some of the debate around Permissivism focuses on these sorts of issues, about the connection between (a) being rational and (b) having true beliefs or accurate credences. Because Permissivists think we can see other beliefs as less eligible than our own, and yet still rational, they're at risk of severing the conceptual link between rationality and truth/accuracy. Greco and Hedden (2016) and Horowitz (2019) focus on the rationality-truth connection in criticising Permissivism. Schoenfield (2019) focuses on the ration ality-accuracy connection in defending Permissivism.
} 
live as a devout Catholic, or an environmental campaigner, or a socialist reformer, isn't just to assent to some theses, or adopt a representation of how things stand, metaphysically and morally. It is to adopt a suite of projects that reach across an extended duration, and which displace rival projects. ${ }^{14}$ With worldview-based projects you resolve to follow a certain way of life, not just by having a specific to-do list in the present, but by trying to guide yourself along a long-range trajectory, and live a life with a particular shape and pattern. Revision is not forbidden, but you shouldn't change course every time you come across a pro tanto good reason to prefer another course. After all, if you undertake a continually-revised succession of projects, you're thereby abandoning the effective pursuit of any longrange projects.

This suggests another explanation of why we needn't see arbitrariness in people's political projects as a worry, the same as arbitrariness in beliefs. In order to have any long-range practical commitments at all you have to throw your lot in, in some sense, with one project or another among the range of projects that you see as rationally eligible for you at the point where you are deciding. If you think you could live your best life by pursuing either project A or B, and you can't pursue both, then you had better find a way to choose one over the other. And if you can't see any deep-seated reason to favour A over B or viceversa, then it seems inevitable that arbitrary factors - e.g. accidents of location, time, or acquaintance - will have an influence in this. By contrast, in forming and revising your beliefs there is no need for anything like this sort of arbitrary leap of faith: one where non-rational inputs into the choice itself lead to commitments which you then have a reason (a defeasible one, but a reason all the same) to see through.

$\mathrm{Ru}$ Ye (2020) offers an intriguing challenge to this position. She thinks practical and epistemic rationality are basically the same with respect to the involvement of arbitrary factors in determining where we end up. The main worry with positing this equivalence, for $Y e$, is that allowing your beliefs to arbitrarily shift direction, sans evidence, seems to place you at risk of carrying out disadvantageous or pointless acts, given how your beliefs guide your actions over time. ${ }^{15}$ But Ye thinks

\footnotetext{
${ }^{14}$ When Rawls and his supporters identify the burdens of judgement, i.e. the factors which explain why reasonable people diverge in their practical, worldview-based commitments, they advert to some factors that pertain to rational belief-formation (e.g. the fact that empirical data are conflicting, or that our concepts are vague and subject to various interpretations), but also several factors that primarily relate to people's goals or ideals (e.g. the fact that values can be shaped by different experiences). Our point isn't to deny that worldviews involve doxastic commitments. Our point is that worldviews involve practical commit ments beyond these doxastic commitments, and that different people's goals or ideals will reflect their varying experiences, allegiances, desires, etc.

${ }^{15}$ For example, if at time to you believe route $A$ is a better way to your destination than route B, and if you know you won't get any new, relevant evidence between to and th, then you should intend to keep believ ing that $\mathrm{A}$ is best at $\mathrm{t}_{1}$. Flip-flopping that isn't prompted by evidence is instrumentally irrational. But if you know that at to you arbitrarily chose to regard A as better than B - if either was rationally permissible, so you just decided randomly - it seems like you aren't rationally bound to keep believing that A is best at $t_{1}$. Rationality doesn't require this, because you arbitrarily decided in the first place, which by your own lights should be seen as irrelevant (Ye 2020: 21).
} 
this problem can be dealt with. She argues that it can be rational for you to choose to undergo something like a transformative experience, in L. A. Paul's (2014) sense. Specifically, you can undergo a doxastically transformative experience, in whose wake you expect that you will come to believe things that you now think false, or vice versa - similar to the results of undergoing a Kuhnian paradigm shift. ${ }^{16}$

How does this suggestion undermine the asymmetry we're positing? The life projects you embark upon are unavoidably subject to arbitrary influences, and so the presence of arbitrary influences doesn't seem to impugn the rationality of your projects. You embark upon some projects, and then you have a (defeasible) reason to see them through, although you may be moved to undergo a transformative experience that orients you towards a whole different set of projects. Ye is claiming that things are similar with your beliefs. Our claim is that practical commitments involve leaps of faith, followed by resolute adherence, whereas beliefs involve continual revision, as the believer dynamically updates her doxastic representation of the world in response to incoming evidence. Ye is saying that beliefs are more like practical commitments than we are suggesting, vis-à-vis the involvement of rationally arbitrary jumping-off points.

The main worry with Ye's proposal is that the motivation for undergoing a doxastically transformative experience is hard to understand. Unless it's the evidence that's compelling you, why should you be open to ricocheting around through a variety of mutually incompatible sets of beliefs? If you think rival sets of beliefs have as much to rationally recommend them as your current set, then you have ways of doxastically capturing your ambivalence about this. And if you don't think other sets of beliefs are as good as your current set, then undergoing experiences that shift your views, sans evidence, seems perverse. The difference with practical commitments is that it is much more difficult to hedge your bets across different options. We don't have effective ways of capturing our ambivalence about different projects we might choose to undertake. Being resolute about the projects we do undertake is a natural response to the fact that we have to choose in the face of ambivalence, in order to have any long-range projects at all.

In sum, then, there are good reasons to be resolute in your practical, worldviewbased commitments, despite the (often inescapable) influence of arbitrary factors in determining which worldview-based commitments you adopt in the first place. There don't seem to be analogous reasons to be similarly resolute in your beliefs. If your beliefs are dynamically responsive to the evidence, then over time arbitrary initial influences in your belief system can and should be 'washed out' of significance, as with a rational Bayesian agent who has eccentric priors, but who has conditionalised on many pieces of evidence.

${ }^{16}$ Thanks to Josh DiPaolo for this suggestion. 


\section{Compromise and mitigating controversy}

According to a popular type of conciliatory view about the epistemology of disagreement, when we find ourselves with a belief that we believe others can reasonably disagree with, rationality requires that we suspend belief or significantly lower our confidence in our beliefs; that we do not court controversy but rather retreat to more neutral ground. ${ }^{17}$ Often when we are confronted with disagreement about how to act we cannot shift to a less controversial practical stance, or pursue a less controversial course of action. For example, suppose you're a member of parliament voting on a bill to raise inheritance tax. You are in favour of the hike, but others disagree with you, and you regard their dissenting views as reasonable. Suppose that it's a free vote, and you don't know if the bill will pass without your vote, because parliament is roughly split. In this case there is no practical option available to you that's less controversial than voting in line with your own view. Voting against the tax is equally controversial, and abstaining will be practically equivalent to voting against it. So, perhaps the contrast between indulgent practical pluralism and indulgent epistemic pluralism is that when there is reasonable disagreement rationality requires that we retreat to less controversial ground. But although this is possible with beliefs - we can suspend or lower our credences - it is often impossible with our actions.

Practical choices do sometimes allow a compromise option, unlike the above case. But even where there is a compromise option, pursuing it might not be less controversial than sticking with a non-compromise position. Suppose in a legislative debate the left-leaning politicians are pushing to relax immigration controls, while those on the right, backed by a majority of their constituents, are pushing to tighten controls. A compromise policy is tabled which tightens restrictions a little, but less than the right-leaning cohort was pushing for. Both the left and the right might end up just as unhappy with the compromise as they were with their opponents' initial proposal. The left may believe that the compromise still infringes the rights of would-be immigrants and damages industries reliant on migrant labour. The right may believe that the policy fails to do justice to their constituents' preference for stricter controls. If the compromise policy is enacted, everyone will oppose it, whereas at least with one of the initial rival policy positions, a large cohort of people would have been satisfied. The compromise option is, in one important respect, more controversial than either non-compromise option. ${ }^{18}$

\footnotetext{
${ }^{17}$ For an introduction see Christensen (2009).

${ }^{18}$ See May (2005: 339). And even if we modify the example so that some people favour the compromise policy, the compromise policy may still be the most controversial option available, if many on the right and left oppose it as strongly as they oppose their opponents' policy.
} 
Not all cases of practical disagreement have this feature. But many do. Adopting a compromise policy around restrictions on abortion won't be acceptable to either pro-lifers or pro-choicers. Adopting a compromise policy on animal rights won't satisfy either vegan activists or eager carnivores. Or consider ethically significant lifestyle choices. Suppose you're trying to decide whether to follow your family's devout religious lifestyle or be a thrill-seeking hedonist. Or suppose you're wrestling with being a well-paid professional and settling down in the suburbs, or being a bohemian artist with nothing tying you down. Middle-ground options may be worse than either extreme, by your own lights. You can try to leave all your options open, but this means postponing the pursuit of any long range projects, and that is a lifestyle choice in its own right - one that seems excessively reticent, to the point of being inferior to the options which you thereby refrain from pursuing.

Examples like these indicate another significant difference between Permissivism and Reasonable Pluralism. In practical contexts being an abstemious pluralist sometimes isn't an option, or else it is an option but pursuing it does nothing to mitigate controversy between parties who hold rival views. But in epistemic contexts hedging options are always available. If you cannot tell which of two inconsistent propositions, $\mathrm{p}_{1}$ or $\mathrm{p}_{2}$, is more likely true, you have ways to represent this ambivalence in your doxastic attitudes. You can withhold belief, or divide your credences between $\mathrm{p}_{1}$ and $\mathrm{p}_{2}$. And using one of these hedging options - e.g. saying "it's reasonable to believe either $\mathrm{p}_{1}$ or $\mathrm{p}_{2}$, and I'm withholding judgement on it" generally is an effective way to mitigate controversy. Suppose you believe there will be a second Covid-19 outbreak, but you hear some thoughtful people making a persuasive case to the contrary. You might continue to lean towards your initial stance, while also thinking it entirely possible that you assessed the evidence incorrectly. (After all, those who disagree with you seem credible, and you already thought it could be reasonable, given the evidence, to believe that there wouldn't be a second outbreak.) Here it seems rationally permissible to withhold belief on the question of whether there will be a second outbreak, and adopting this view seems to lessen the controversy between you and others.

We think this provides another good explanation of why one needn't find arbitrariness in practical commitments as concerning as arbitrariness in beliefs. In cases where you recognise a range of rational doxastic attitudes that you might take on a proposition, given certain evidence, without any decisive consideration favouring one above the others, you have the option of suspending belief or distributing your credences, and this will lead you to have a doxastic attitude that's no less rationally acceptable by your own lights, and (typically) more acceptable to others. ${ }^{19}$ Being conciliatory mitigates controversy, whereas arbitrarily sticking

\footnotetext{
${ }^{19}$ One might doubt whether suspending belief in response to reasonable disagreement about p is really a less controversial response than believing either $\mathrm{p}$ or not- $\mathrm{p}$. We can imagine a debate where two sides disagree about what the evidence supports, but both are adamant that it supports a belief one way or the
} 
to your guns perpetuates it, and when you think that there are a range of reasonable alternative positions, rationality requires not courting controversy by picking one rather than the other.

By contrast, in cases where you see a range of incompatible, practically rational courses of action, without any good reason recommending one above the others, arbitrarily pursuing one of them will often be better, since compromise options may be less agreeable than any individual course of action. In a practical context, arbitrarily preferring one course of action seems acceptable, because being conciliatory leads towards compromise options that no-one likes, thus increasing - or at least not mitigating - controversy. Although rationality requires that we do not court controversy, in the practical case compromising courts controversy more than sticking to one's guns; the same is not true of epistemic commitment.

Against this sort of thinking, Daniel Weinstock (2013: 545-46) argues that compromises like in the immigration policy example actually do mitigate controversy. An example will help illustrate. Suppose Libertarian Liz regards any taxation beyond what's strictly needed for a minimal state as unacceptable, while Socialist Sophie thinks we should tax 100\% of income over £30k, the national average. Liz and Sophie have strong views, but suppose they aren't arrogant, and they regard each other's views as reasonable. Suppose they're trying to agree upon an income tax policy. A centrist compromise policy taxing 50\% of income over £30k seems to assign some weight to the two conflicting ideals, liberty and equality, which underpin Liz and Sophie's rival views. If Sophie accepts that Liz's view is reasonable, then presumably she must think there is something to be said for an ideal of liberty that recommends massive tax cuts. And if Liz sees Sophie's view as reasonable, then it seems like she must think there is something to be said for an ideal of equality that recommends tax hikes. While neither Liz nor Sophie would individually support the centrist compromise policy, both can recognise this policy as one that assigns some weight to both ideals, whereas either of their individually preferred policies accords total priority to one ideal or the other. The compromise policy may therefore be less controversial, in a certain sense, insofar as it is more ecumenical with respect to the ideals to which it assigns some weight. Hence if you take the epistemic credentials of those with whom you disagree seriously, this can lead you to regard a practical compromise as less controversial, even if it is an option that neither you nor your opponent would individually favour. ${ }^{20}$

other, and that suspension of belief is irrational. In such a case suspending belief will be more controversial than believing p or not-p, similar to adopting a compromise policy in the immigration case.

${ }^{20}$ See Kappel (2018: 88-89), and for discussion, Rowland (forthcoming, chapter 8). The kind of public reason liberalism espoused by Rawls and others aims at controversy-mitigation in something like the sense that Weinstock describes. But critics of public reason liberalism may of course argue that this kind of controversy-mitigation isn't as effective as it seems, since, as per our analysis in the previous paragraph, it can easily result in compromise policies that everyone regards as second-best, at best. 
Weinstock, however, does not think that we can always practically compromise in this way. Furthermore, we might think that although there is a way in which the centrist compromise tax policy is less controversial in the sense that it takes into account both the ideal that Liz prioritises and the ideal that Sophie prioritises, it is no less controversial in an important sense. When we suspend belief about whether $\mathrm{p}$ in light of disagreement in belief about whether $\mathrm{p}$, we no longer take a stance on the issue. If Liz or Sophie accept the centrist policy, they do not refrain from taking a stance; they merely take a different stance. So, even if Weinstock is right that there is a sense in which compromise policies mitigate controversy, this fact does not challenge the explanation of the difference between indulgent epistemic pluralism and indulgent practical pluralism that we have been providing. There is still an important sense in which we cannot mitigate practical controversy in the way that we can mitigate epistemic controversy.

Ultimately these issues are all about how ready we should be to agree to disagree on controversial matters. We should be pluralistic about people's political commitments, and this doesn't mean we have to let go of our own substantive political commitments. This can generate a sense of arbitrariness, granted, but this is the lesser of two evils, since the alternatives are either to give up most of one's practical commitments, or (worse) to give up on political pluralism. On the other hand, we shouldn't be too eager to agree to disagree on purely epistemic matters. Beliefs needn't be resolute, and adopting ambivalent or hedged doxastic attitudes around controversial claims is often a way to mitigate epistemic controversy. The upshot of our discussion is that we shouldn't let our worries about the arbitrariness of being an epistemic indulgent pluralist infect our thinking about indulgent pluralism in people's political commitments. ${ }^{21}$ There are differences between the epistemic and practical domains, which justify us in being more tolerant of arbitrariness in the latter case. ${ }^{22}$

\section{References}

Cowie, Christopher (2014), "In defence of instrumentalism about epistemic normativity", Synthese 191: 4003-17.

Christensen, David (2009), "Disagreement as evidence: the epistemology of controversy", Philosophy Compass 4 (5): 756-767.

\author{
Finlay, Stephen and Mark Schroeder \\ (2017), "Reasons for action: internal vs. \\ external", The Stanford Encyclopedia of Phi- \\ losophy (Fall 2017 Edition), Edward N. \\ Zalta (ed.), plato.stanford.edu/ar- \\ chives/fall2017/entries/reasons-inter- \\ nal-external.
}

\footnotetext{
${ }^{21}$ However, certain kinds of indulgent practical pluralism, such as certain forms of public reason liberalism, may have epistemic commitments and commitments regarding epistemic pluralism, see van Wietmarschen (2018).

${ }^{22}$ Thanks to Josh DiPaolo, Elizabeth Edenberg, and two anonymous referees, for feedback on an earlier draft of this chapter.
} 
Greco, Daniel, and Brian Hedden (2016),

"Uniqueness and metaepistemology", The Journal of Philosophy 113 (8): 365-95.

Horowitz, Sophie (2019), "The truth problem for permissivism", The Journal of Philosophy 116 (5): 237-62.

Jackson, Elizabeth (2020), "A defense of intrapersonal belief permissivism”, forthcoming in Episteme.

Kappel, Klemens (2018). "How moral disagreement may ground principled moral compromise", Politics, Philosophy e Economics 17 (1): 75-96.

May, Simon Cabulea (2005), "Principled compromise and the abortion controversy", Philosophy \& Public Affairs 33 (4): $317-48$.

Paul, L. A. (2014), Transformative Experience (Oxford: Oxford University Press).

Quong, Jonathan (2010), Liberalism without Perfection (Oxford: Oxford University Press).

Rawls, John (1993), Political Liberalism (New York: Columbia University Press).

Rowland, Richard (2012), "Moral error theory and the argument from epistemic reasons", Journal of Ethics and Social Philosophy 7 (1): 1-24.

(forthcoming), Moral Disagreement (Abingdon: Routledge).

Schoenfield, Miriam (2014), "Permission to believe: why permissivism is true and what it tells us about irrelevant influences on belief", Noûs 48 (2): 193-218.

(2019), "Permissivism and the value of rationality: a challenge to the uniqueness thesis", Philosophy and Phenomenological Research 99 (2): 286-97.

Schultheis, Ginger (2018), "Living on the edge: against epistemic permissivism", Mind 127 (507): 863-79.

Schroeder, Mark (2007), Slaves of the Pas sions (Oxford: Oxford University Press).
Shah, Nishi (2006), "A new argument for evidentialism”, Philosophical Quarterly 56 (225): 481-98.

Sharadin, Nathaniel (2017), "A partial defence of permissivism”, Ratio 30 (1): 57 71.

Simpson, Robert Mark (2017), "Permissivism and the arbitrariness objection", Episteme 14 (4): 519-38.

Smith, Julia Jael (2020), "Unacknowledged permissivism”, Pacific Philosophical Quarterly 101 (1): 158-83.

Stapleford, Scott (2019), "Intraspecies impermissivism”, Episteme 16 (3): 34056.

Steglich-Petersen, Asbjørn (2011), "How to be a teleologist about epistemic reasons" in Asbjørn Steglich-Petersen and Andrew Reisner (Eds.), Reasons for Belief (Cambridge: Cambridge University Press).

Weinstock, Daniel (2013), "On the possibility of principled moral compromise", Critical review of International Social and $\mathrm{Po}$ litical Philosophy 16 (4): 537-56.

White, Roger (2005), "Epistemic permissiveness", Philosophical Perspectives 19: 445-59.

van Wietmarschen, Han (2018), "Reasonable citizens and epistemic Peers: a skeptical problem for political liberalism", Journal of Political Philosophy 26 (4): 486-507.

Williams, Bernard (1973), Problems of the Self (Cambridge: Cambridge University Press).

(1981), "Internal and External Reasons" in Moral Luck (Cambridge: Cambridge University Press).

Ye, Ru (2020), "The arbitrariness objection against permissivism", forthcoming in Episteme. 